\title{
Evaluation of the electric vehicle impact in the power demand curve in a smart grid environment
}

\author{
Hugo Morais, Tiago Sousa, Zita Vale, Pedro Faria
}

A B S T R A C T

Smart grids with an intensive penetration of distributed energy resources will play an important role in future power system scenarios. The intermittent nature of renewable energy sources brings new challenges, requiring an efficient management of those sources. Additional storage resources can be beneficially used to address this problem; the massive use of electric vehicles, particularly of vehicle-to-grid (usually referred as gridable vehicles or V2G), becomes a very relevant issue. This paper addresses the impact of Electric Vehicles (EVs) in system operation costs and in power demand curve for a distribution network with large penetration of Distributed Generation (DG) units. An efficient management methodology for EVs charging and discharging is proposed, considering a multi-objective optimization problem. The main goals of the proposed methodology are: to minimize the system operation costs and to minimize the difference between the minimum and maximum system demand (leveling the power demand curve). The proposed methodology perform the day-ahead scheduling of distributed energy resources in a distribution network with high penetration of DG and a large number of electric vehicles. It is used a 32bus distribution network in the case study section considering different scenarios of EVs penetration to analyze their impact in the network and in the other energy resources management.

Keywords:

Distributed generation

Power demand curve

Mixed-integer linear programming

Smart grid

Vehicle-to-grid

\section{Introduction}

The improvements made in recent years in the power systems allows the large scale integration of Distributed Generation (DG) units $[1,2]$. However, generation technologies based on renewable energy sources, as the case of wind and sun, introduce new constraints in the system management [3,4]. Currently, in many situations, DG units must be disconnect due to technical system constraints, with huge impacts in the economic point of view of the operation of these resources, as the case of influencing the market clear price [5]. Pumping hydro plants have been used to minimize the impact of DG units in power systems [6,7]. However, the increasing accommodation of renewable based resources requires even more increased capacity of these or other plants; pumping hydro plants became insufficient in the majority of the countries. The use of storage units is a promising solution; however, the high cost of these units inhibits their intensive use [8-10]. The future massive use of Electrical Vehicles (EVs) with discharge capability, usually referred as Vehicle-to-Grid (V2G) represents a storage capacity with huge management flexibility. V2G can consume the excess generation in off-peak hours and ensure some services (ancillary services, voltage stability or peak reduction) in peak hours [11]. On the other hand, the use of EVs can reduce the greenhouse gas emissions, mainly in large cities, where the pollution is a critical issue.

Besides the advantages of V2G usage, the massive use of EV and V2G makes power system management, operation and planning more complex [12]. In order to fully benefit from the advantages of V2G and not to increase the power demand in peak hours, it is necessary to undertake an efficient management of V2G charge and discharge. The methods to be used must take into consideration V2G users' profiles and requirements, and they must be combined with adequate business models [13] allowing the control of charge and discharge processes by the VPP through an established payment/remuneration, according to the defined rules. Improved and adequate optimization methods are required for this purpose. These methods should be able to deal with problems with a large number of variables and constraints. Moreover, solutions should be developed in a way they can provide solutions rapidly, in order to cope with operation time constraints. The massive use of EVs can improve the day-ahead scheduling, because the EV can be seen as a controlled load or a controlled generator (with V2G capacity) [11]. The combination of EVs with other renewable resources can 
help reducing the use of traditional thermoelectric power plants based on fossil fuels.

The most recent literature in the field of the present paper includes the work presented in [14,15]. In [14] is proposed a methodology to schedule the charge and the discharge process of the EVs and PHEVs. Generation, consumption, EVs trips, and market prices uncertainties are considered. The aim is to balance the system based in the UK market prices. These market prices are used as reference to schedule the EVs charge and discharge in order to obtain the load leveling. In fact, with this methodology is possible to obtain a good solution but not the optimal solution. Rules are applied to model the constraints of the problem; only one period (15 min) in each rule set is considered. Thus, each vehicle charge process only takes into account the necessities for its trips and not the system necessities. Moreover, network technical constraints are not considered.

In [15] is proposed another interesting peak shaving and valley filling methodology considering V2G. The system considers two control levels, namely the smart grids control center and the V2G control center. The smart grids control center send control signals to the V2G control centers based on "optimal energy distribution" and the V2G control centers are responsible to control the charge and discharge process of V2G. The forecasted load and hourly consumption targets imposed by the user are considered. The objective function minimizes the differences between the target and the actual power demand (load consumption plus the EVs charge minus the EVs discharge).

The present paper analyzes the impact of V2G in system operation costs and in the power demand curve for a distribution network with large penetration of distributed energy resources. This impact is analyzed from different perspectives: minimizing the operation cost and minimizing the difference between the maximum and minimum demand during $24 \mathrm{~h}$ of day. A multi-objective problem is also proposed considering the minimization of operation cost and the power demand curve optimization. In the proposed methodology, the impact of different number of EVs in the distribution network is analyzed considering the vehicles' characteristics and use profiles, according the report of the US Department of Transportation [16].

The power demand curve optimization aims to increase the minimum load consumption and/or to decrease the maximum load consumption, resulting in a power demand curve closer to a rectangular shape. The power demand curve can be evaluated analyzing the load factor value. The load factor can be obtained relating the total energy consumption with the peak consumption in a specific time-horizon. In the present paper, it is analyzed 1 day, i. e., (24 periods of $1 \mathrm{~h}$ ).

After this introduction section, Section 2 presents some concepts related to electric vehicles. Section 3 presents the developed methodologies, and Section 4 presents an illustrative case study that considers a 32-bus network with intensive use of distributed generation. Finally, the most important conclusions of the work are presented in Section 5.

\section{Electric vehicles in smart grids}

The present section addresses the classification of the electric vehicles technologies, and their impact in the power system.

\subsection{Type of electric vehicles}

Electric Vehicles (EVs) can be defined as vehicles which use an electric motor to provide mechanical shaft power, allowing driving the wheels. The main difference between EVs and conventional vehicles relies on the energy source used to supply the engine. Conventional vehicles use an internal combustion engine supported by fuel (namely gasoline or diesel) to activate the engine.

In many papers, EVs are divided into three categories, depending on the type of on-board energy source [17-20]: the Battery Electric Vehicle (BEV), the Plug-in Hybrid Electric Vehicle (PHEV) and the Fuel Cell Vehicle (FCV).

- Battery Electric Vehicle: BEVs use the battery as the main power source. However, some BEVs use extra systems to support the batteries, such as the ultracapacitor. The BEV contains an electric motor, batteries and power electronics. Several batteries technologies can be used providing different performances to the electric vehicles [21].

- Plug-in Hybrid Electric Vehicle: A hybrid electric vehicle uses two or more energy supplies/sources to propel the vehicle, being one of these sources an electrical energy engine [22,23]. The concept of PHEV emerges when a model similar to the HEV is developed, with the possibility of connecting it to the electric network [24].

- Fuel Cell Vehicle: A fuel cell unit is used to generate power, either to supply the electric motor or to store energy in the battery. FCVs are less likely to be competitive in a near future, when compared to BEV and PHEV, because fuel cell units are currently very expensive [17].

In this paper, the term EV refers to both BEV and PHEV vehicles; FCV is not considered.

\subsection{Impact of electric vehicles}

The use of EVs as another energy resource can bring more problems to the network grid, namely to distribution networks. Several authors point out that a large amount of EVs in the charging mode can have a negative influence in distribution networks [25]. It is possible that new power demand peaks appear in inappropriate periods, and that the voltage drops increase. Several studies evaluate the performance of the distribution network considering three types of strategies [26]:

\section{- Uncoordinated charging. \\ - Smart charging. \\ - Smart charging/discharging.}

The uncoordinated charging occurs when vehicles connect to the distribution network and start immediately to charge until they achieve the battery's maximum capacity. The smart charge and discharge consists in the network operator controlling the time and the power of EVs charge/discharge. The network operator will decide on when the most suitable periods for charging/discharging occur and on the amount of power [27]. Different goals can be considered in the charge/discharge scheduling, namely the operation costs minimization, the greenhouse gas emissions minimization [28] or the load variations minimization [29].

The EV user will indicate the energy that should be stored in the battery at specific periods. This smart control will be integrated in the smart grid with the purpose of helping the system operation controlling the EVs charges. They can additionally be used as generators, to reduce the demand in peak periods. The management of charging/discharging processes in parking lots are pointed in [30] as a possible solution.

The smart control of EVs (smart charging/discharging) has been used in this paper, due to the reasons pointed above that are related to the impact of EVs in the distribution network. 


\section{Energy resources management methodology}

The energy resources management is an important task in the present power systems operation, mainly in the transmission level. However, in the future, power systems with large penetration of distributed energy resources in distribution networks are also important in order to develop innovative methodologies to manage a large set of energy resources, such as distributed generation and electric vehicles. In this paper, it is proposed a methodology for the distributed energy resources scheduling, considering the operation cost and the load factor.

A multi-objective function has been used to evaluate the impact of EVs in the distribution network. The first objective function tries to minimize the operation cost of the available energy resources, namely the use of DG and of electric-vehicles. In the operation cost, there is also considered the energy acquisition to external suppliers and the penalties with non-supplied demand ${ }^{1}$ and with "take-or-pay" contracts. ${ }^{2}$ The second objective tries to optimize the load factor (equal to 1), i.e., it tries to minimize the differences between the maximum and the average power demand in a distribution network considering 1 day as the time-horizon. The use maximum and average demand values in the objective function turns the function into a non-convex function, increasing the complexity to obtain the problem global optimum. The considered constraints include the technical distributed generation constraints and EV constraints.

\subsection{Constraints}

In this section, the constraints used in the optimization problem are described, regardless the objective function used the optimization problem will be subjected to the following constraints:

\subsubsection{Network power balance (1) in each period $t$}

The generation power must meet the system demand. The generation side considers DG units, external suppliers and the discharge power from EVs. On the other hand, the system demand side considers the power demand of the consumers, and the consumption corresponding to EVs battery charging. The balance is performed for each period $t$.

$$
\begin{aligned}
& \sum_{D G=1}^{N_{D G}}\left(P_{D G(D G, t)}-P_{P G C(D G, t)}\right)+\sum_{S=1}^{N_{S}} P_{S p(S, t)}+\sum_{V=1}^{N_{V}} P_{D c h(V, t)} \\
& =\sum_{L=1}^{N_{L}}\left(P_{L o a d(L, t)}-P_{N S D(L, t)}\right)+\sum_{V=1}^{N_{V}} P_{C h(V, t)} \quad \forall t \in 1, \ldots, T
\end{aligned}
$$

where

$\begin{array}{ll}N_{D G} & \text { Total number of distributed generators } \\ N_{L} & \text { Total number of loads } \\ N_{S} & \text { Total number of external suppliers } \\ N_{V} & \text { Total number of electric vehicles } \\ P_{C h(V, t)} & \text { Active power charge of vehicle } V \text { in period } t(\mathrm{~W}) \\ P_{D G(D G, t)} & \text { Active power generation of distributed generation } \\ & \text { unit } D G \text { in period } t(\mathrm{~W}) \\ P_{D c h(V, t)} & \text { Active power discharge of vehicle } V \text { in period } t(\mathrm{~W}) \\ P_{\text {Load }(L, t)} & \text { Active power demand of load } L \text { in period } t(\mathrm{~W})\end{array}$

\footnotetext{
${ }^{1}$ Non-supplied demand: energy required by consumers, but not supplied.

2 "Take-or-Pay" contracts: a provision, written into a contract, whereby the system operator has the obligation of either taking generated energy or paying a specified amount.
}

$P_{N S D(L, t)} \quad$ Active power non-supplied demand for load $L$ in period $t(\mathrm{~W})$

$P_{P G C(D G, t)}$ Power generation curtailed of $D G$ unit in period $t$ (W)

$P_{S P(S, t)} \quad$ Active power generation of external supplier $S$ in period $t(\mathrm{~W})$

$T$ Total number of periods

\subsubsection{Maximum and minimum distributed generation limits (2)-(4) in each period $t$}

The maximum and minimum generation limits depend on the technology used in each distributed generation unit. In this work, three different approaches to model the DG generation limits are presented. Eq. (2) is used to model the thermal unit behavior with a minimum and a maximum generation limits. DG units using natural resources are modeled as in Eq. (3), considering the minimum generation equal to zero, and the maximum limit is established based on a forecast process. Eq. (4) is applied to DG units with "take-or-pay" contracts. These contracts are used to mitigate the loss due to power curtailment and are mainly used for distributed generation units based on renewable sources such as the wind and solar. In these cases, it is necessary to add the generation curtailment to the generation power of these units. The generation curtailment is an extra cost for the VPP related with the DG curtailment.

$$
\begin{aligned}
& P_{D G M i n(D G, t)} \times X_{D G(D G, t)} \leqslant P_{D G(D G, t)} \leqslant P_{D G M a x(D G, t)} \times X_{D G(D G, t)} \\
& t \in\{1, \ldots, T\} ; D G \in\left\{1, \ldots, N_{D G}\right\} ; X_{D G(D G, t)} \in\{0,1\} \\
& 0 \leqslant P_{D G(D G, t)} \leqslant P_{D G F o r(D G, t)} ; t \in\{1, \ldots, T\} ; D G \in\left\{1, \ldots, N_{D G}\right\} \\
& \begin{aligned}
P_{D G(D G, t)}+P_{P G C(D G, t)} & =P_{D G F o r(D G, t)} ; t \in\{1, \ldots, T\} ; D G \\
& \in\left\{1, \ldots, N_{D G}\right\}
\end{aligned}
\end{aligned}
$$

where

\begin{tabular}{ll}
\hline$P_{D G F o r(D G, t)}$ & $\begin{array}{l}\text { Active power generation forecast of } D G \text { unit in } \\
\text { period } t(\mathrm{~W})\end{array}$ \\
$P_{D G M a x(D G, t)}$ & $\begin{array}{l}\text { Maximum active power generation of } D G \text { unit in } \\
\text { period } t(\mathrm{~W})\end{array}$ \\
$P_{D G M i n(D G, t)}$ & $\begin{array}{l}\text { Minimum active power generation of } D G \text { unit in } \\
\text { period } t(\mathrm{~W})\end{array}$ \\
$X_{D G(D G, t)}$ & Binary variable of $D G$ unit in period $t(\mathrm{~W})$
\end{tabular}

\subsubsection{Maximum external supplier power limit (5) in each period $t$}

In order to supply all the required demand, the methodology considers the use of energy provided by external suppliers. This energy can be obtained through bilateral contracts or in the market negotiation. In each period $t$, the power supplied by the external suppliers is limited by the established contracts and/or by the market transactions.

$0 \leqslant P_{S p(S, t)} \leqslant P_{\text {SpLimit }(S, t)} ; \forall t \in\{1, \ldots, T\} ; \forall S \in\left\{1, \ldots, N_{S}\right\}$

where $\begin{array}{ll}P_{S P L i m i t}(S P, t) & \begin{array}{l}\text { Maximum active power generation of external } \\ \text { supplier } S \text { in period } t(\mathrm{~W})\end{array}\end{array}$ 
3.1.4. Battery balance (6) of electric vehicle $V$ in period $t$

Eq. (6) is used to determine the amount of energy stored at the end of period $t$. It is necessary to consider the typical daily travel profile of the electric vehicle, and this data is considered in variable $E_{T r i p(V, t)}$. In order to satisfy the daily travel profile, the system operator should use adequate forecast methods to know the daily travel profile. This daily travel profile can be also indicated by the user to the system operator, through an adequate communication system between all players [31]. The battery balance also needs to consider the energy remaining from the previous period, and the charge/discharge in period $t$. Additionally, the efficiency of charge $\left(\eta_{c(V)}\right)$ and discharge $\left(\eta_{d(V)}\right)$ processes are considered for each electric vehicle.

$E_{\text {Stored }(V, t)}=E_{\text {Stored }(V, t-1)}-E_{\text {Trip }(V, t)}+\Delta t \times\left(\eta_{c(V)} \times P_{C h(V, t)}-\frac{1}{\eta_{d(V)}} \times P_{D c h(V, t)}\right)$
$\forall t \in\{1, \ldots, T\} ; \forall V \in\left\{1, \ldots, N_{V}\right\} ; \Delta t=1 ; t=1 \rightarrow E_{\text {Stored }(V, t-1)}=E_{\text {Initial }(V)}$

where

$\begin{array}{ll}\Delta t & \text { Elementary period (e.g. } 30 \mathrm{~min} .(0.5), 1 \mathrm{~h}(1))(\mathrm{h}) \\ \eta_{c(V)} & \text { Grid-to-vehicle efficiency } \\ \eta_{d(V)} & \text { Vehicle-to-grid efficiency } \\ E_{\text {Initial }(V)} & \begin{array}{l}\text { Energy stored of the electric vehicle } V \text { in the } \\ \text { beginning of period } 1(\mathrm{~W} \mathrm{~h})\end{array} \\ E_{S t o r e d(V, t)} & \begin{array}{l}\text { Energy stored in electric vehicle } V \text { at the end of } \\ \text { period } t(\mathrm{~W} \mathrm{~h})\end{array} \\ E_{\text {Trip }(V, t)} & \begin{array}{l}\text { Energy consumption during a trip of the electric } \\ \text { vehicle } V \text { in period } t(\mathrm{~W} \mathrm{~h})\end{array}\end{array}$

3.1.5. Battery capacity limit (7) and minimum stored energy (8) for each electric vehicle $V$

The energy stored in the batteries in each period $t$ must be lower than or equal to the battery capacity (Eq. (7)). Eq. (8) ensures that the battery of each electric vehicle $V$ always contains a minimum amount of energy. This can be seen as a reserve energy which can be used for an unexpected travel in each period $t$, and to avoid the fast degradation of EVs' batteries.

$$
\begin{aligned}
& E_{\text {Stored }(V, t)} \leqslant E_{\text {BatCap }(V)} ; \forall t \in\{1, \ldots, T\} ; \forall V \in\left\{1, \ldots, N_{V}\right\} \\
& E_{\text {Stored }(V, t)} \geqslant E_{\text {MinCharge }(V, t)} ; \forall t \in\{1, \ldots, T\} ; \forall V \in\left\{1, \ldots, N_{V}\right\}
\end{aligned}
$$

where

\begin{tabular}{ll}
$E_{\text {BatCap }(V)}$ & $\begin{array}{l}\text { Battery energy capacity of electric vehicle } V \\
(\mathrm{Wh})\end{array}$ \\
$E_{\text {MinCharge }(V, t)}$ & $\begin{array}{l}\text { Minimum stored energy to be guaranteed at the } \\
\text { end of period } t, \text { for electric vehicle } V(\mathrm{~W} h)\end{array}$ \\
\hline
\end{tabular}

3.1.6. Discharge limit ( 9 and 10) for each electric vehicle $V$ considering the battery discharge rate

The EVs discharge process is limited by technical constraints of charging/discharging sites. According to this, it is important to limit the maximum discharging rate to the maximum rate allowed by the charging/discharging points.

$$
\begin{aligned}
& P_{D c h(V, t)} \leqslant P_{\text {DchLimit }(V, t)} \times X_{C h(V, t)} \\
& \forall t \in\{1, \ldots, T\} ; \forall V \in\left\{1, \ldots, N_{V}\right\} ; X_{C h(V, t)} \in 0,1
\end{aligned}
$$

$\frac{1}{\eta_{d(V)}} \times P_{D c h(V, t)} \times \Delta t \leqslant E_{S t o r e d(V, t-1)}-E_{T r i p(V, t)}$

$\forall t \in\{1, \ldots, T\} ; \forall V \in\left\{1, \ldots, N_{V}\right\}$

where

$P_{\text {Dchlimit }(V, t)}$ Maximum active power discharge of electric vehicle $V$ in period $t(\mathrm{~W})$

3.1.7. Charge limit (11 and 12) for each electric vehicle $V$ considering the battery charge rate

The charge rates are also limited by the technical characteristics of the charging/discharging site.

$P_{C h(V, t)} \leqslant P_{C h L i m i t(V, t)} \times X_{D c h(V, t)}$

$\forall t \in\{1, \ldots, T\} ; \forall V \in\left\{1, \ldots, N_{V}\right\} ; X_{D c h(V, t)} \in 0,1$

$\eta_{c(V)} \times P_{C h(V, t)} \times \Delta t \leqslant E_{\text {BatCap }(V)}-E_{S t o r e d(V, t-1)}-E_{\text {Trip }(V, t)}$

$\forall t \in\{1, \ldots, T\} ; \forall V \in\left\{1, \ldots, N_{V}\right\}$

where
$P_{\text {ChLimit }(V, t)} \quad$ Maximum active power charge of electric vehicle $V$ in period $t(\mathrm{~W})$

3.1.8. Vehicle charge and discharge are not simultaneous (13) in electric vehicle $V$ in period $t$

To avoid the EV's batteries charge and discharge in the same period $t$, two binary variables $\left(X_{C h(V, t)}\right.$ and $\left.X_{D c h(V, t)}\right)$ were included.

$X_{C h(V, t)}+X_{D c h(V, t)} \leqslant 1$

$\forall t \in\{1, \ldots, T\} ; \forall V \in\left\{1, \ldots, N_{V}\right\} ; X_{C h(V, t)}$ and $X_{D c h(V, t)} \in 0,1$

where

$\begin{array}{ll}X_{C h(V, t)} & \begin{array}{l}\text { Binary variable of electric vehicle } V \text { related to power } \\ \text { charge in period } t\end{array} \\ X_{D c h(V, t)} & \begin{array}{l}\text { Binary variable of electric vehicle } V \text { related to power } \\ \text { discharge in period } t\end{array}\end{array}$

\subsection{Operation cost optimization}

The first objective function consists in the minimization of the operation cost, which it is represented by function $f_{1}$ in Eq. (15). The main goal is to operate the distributed energy resources at the lowest possible cost. The energy resource costs are represented by a linear cost function. The EVs are seen as another distributed energy resource to the system operator, requiring the inclusion of costs with the discharge and charge. The system operator will have to pay the EVs discharged energy, and when the EVs users need to charge their vehicles the system operator will receive a payment for supplying the required amount of energy. In order to use the concept of vehicle-to-grid in a sustainable way, the remuneration tariffs applied to the EVs batteries that provide energy to the grid, must be carefully planned and must be well above the batteries' degradation cost. The degradation cost $(D C)$ can be obtained using Eq. (14) proposed in [32]. 


$$
\begin{aligned}
\text { degradation cost }= & \frac{\text { replacement cost } \times \text { V2GDeg }}{0.8-1} \\
& \times \text { percent of battery used }
\end{aligned}
$$

Considering the example presented in [33] for a lithium iron phosphate battery $\left(\mathrm{LiFePO}_{4}\right)$, the degradation factor (V2GDeg) is $-2.71 \mathrm{E}^{-5}$; the replacement cost for a $16 \mathrm{~kW} \mathrm{~h}$ battery pack is around 5000 USD, leading to a degradation cost of $0.042 \$ / \mathrm{kW} \mathrm{h}$.

Function $f_{1}$ considers the operation cost with the distributed generation units, external suppliers, the EVs discharge, the EVs charge, the non-supplied demand and the power generation curtailed.

$$
\begin{aligned}
\min f_{1}= & \sum_{t=1}^{T}\left[\sum_{D G=1}^{N_{D G}}\left(c_{D G(D G, t)} \times P_{D G(D G, t)}+c_{P G C(L, t)} \times P_{P G C(L, t)}\right)\right. \\
& \left.+\sum_{S=1}^{N_{S}} c_{S p(S, t)} \times P_{S p(S, t)}+\sum_{V=1}^{N_{V}} c_{D c h(V, t)} \times P_{D c h(V, t)}+\sum_{L=1}^{N_{L}} c_{N S D(L, t)} \times P_{N S D(L, t)}\right]
\end{aligned}
$$

where

\begin{tabular}{ll}
$c_{D G(D G, t)}$ & $\begin{array}{l}\text { Generation cost of } D G \text { unit in period } t \text { (m.u./W) } \\
c_{D c h(V, t)}\end{array}$ \\
$c_{N S D(L, t)}$ & $\begin{array}{l}\text { Discharge price of electric vehicle } V \text { in period } t \\
\text { Non-supplied demand cost of load } L \text { in period } t \\
\text { (m.u./W) }\end{array}$ \\
$c_{P G C(D G, t)}$ & $\begin{array}{l}\text { Power generation curtailed cost of } D G \text { unit in period } \\
t(\text { m.u./W) }\end{array}$ \\
$c_{S p(S, t)}$ & $\begin{array}{l}\text { Market energy price of upstream supplier } S \text { in } \\
\text { period } t(\text { m.u./W) }\end{array}$ \\
\hline
\end{tabular}

The inclusion of non-supplied demand and power generation curtailed costs has the objective of presenting a robust mathematical formulation, which deals with critical situations in the electric network managed by the aggregators. The non-supplied demand is activated when the supply is not enough to balance the load demand, and consumers will be paid for the non-supplied demand power. The power generation curtailed is important for the "take or pay" contracts that the system operator establishes with some DG units (e.g. photovoltaic units). In these situations, when the load is lower than this generation, the value of power generation curtailed will be the difference between both.

This first objective function is subjected to the constraints presented in Section 3.1 (see Eqs. (1)-(13). The mathematical formulation has been implemented in Generic Algebraic Modeling System (GAMS) software [34].

\subsection{Power demand curve optimization}

The second objective function consists in the power demand curve optimization (see Eq. (17)), trying to put the load factor equal to 1 . The load factor (Eq. (16)) is obtained considering the total energy consumption and the peak-demand considering a specific time-horizon. In the present methodology the time-horizon is 1 day (24 periods of 1 hour).

LoadFactor $=\frac{E}{P_{\max } \times T}=\frac{P_{\text {avg }}}{P_{\max }}$

where

$\begin{array}{ll}E & \begin{array}{l}\text { Total energy consumption in a specific time } \\ \text { horizon }(\mathrm{W} \mathrm{h})\end{array} \\ \text { LoadFactor } & \text { Load factor of the load diagram to a specific time }\end{array}$

horizon $T$, usually for $24 \mathrm{~h}$

$P_{a v g} \quad$ Average active power demand of load diagram in a specific time horizon (W)

$P_{\max } \quad$ Maximum active power demand of load diagram in a specific time horizon (W)

$P_{\min } \quad$ Minimum active power demand of load diagram in a specific time horizon (W)

The use of electric vehicles and other storage systems can balance the power demand curve [35], charging energy in the off-peak hours and discharging energy in peak-hours. The constant power demand turns the system more predictable and easier to manage, and the cost of energy more regular during the day [36]. The proposed methodology tries to minimize the difference between the average and the maximum power demand. However, it is important the inclusion of the non-supplied demand and of power generation curtailed costs in the objective function to penalize their use, avoiding the curtailment of all loads. In Eq. (17), a penalty factor represented by variable $P F$ is used in the non-supplied demand and power generation curtailment costs.

$$
\begin{aligned}
\min f_{2}= & \left(1-\frac{\operatorname{avg}_{t \in\{1, \ldots, T\}}\left(\sum_{L=1}^{N_{L}}\left(P_{\text {Load }(L, t)}-P_{N S D(L, t)}\right)+\sum_{V=1}^{N_{V}}\left(P_{C h(V, t)}-P_{\text {Dch }(V, t)}\right)\right)}{\max _{t \in\{1, \ldots, T\}}\left(\sum_{L=1}^{N_{L}}\left(P_{L \operatorname{Lod}(L, t)}-P_{N S D(L, t)}\right)+\sum_{V=1}^{N_{V}}\left(P_{C h(V, t)}-P_{D c h(V, t)}\right)\right)}\right) \\
& \left.+P F \times \sum_{t=1}^{T} \sum_{D G=1}^{N_{D C}}\left(P_{P G C(D G, t)}\right)+\sum_{L=1}^{N_{L}}\left(P_{N S D(L, t, t)}\right)\right)
\end{aligned}
$$

where

PF

Penalty factor

The use of the average and maximum expressions in function $f_{2}$ turns this function into a complex and non-convex one. This fact makes the power demand curve optimization a non-convex optimization problem, in which it could take a long time to find the optimal solution [37]. To transform Eq. (17) into a convex one, the authors propose the use of Eq. (18). The load demand curve is normally evaluated using the load factor. However, the main goal is to reduce the difference between the peak and off-peak demand during 1 day. In this away, in Eq. (18), the load factor is changed by a daily load demand range factor $\left(P_{\max }-P_{\min }\right)$, removing the average power variable.

$$
\begin{aligned}
& \min f_{2}=\max _{t \in\{1, \ldots, T\}} \sum_{L=1}^{N_{L}}\left(P_{L o a d}(L, t)-P_{N S D(L, t)}\right) \\
& \left.+\sum_{V=1}^{N_{V}}\left(P_{C h(V, t)}-P_{D c h(V, t)}\right)\right)-\min _{t \in\{1, \ldots, T\}} \sum_{L=1}^{N_{L}}\left(P_{\operatorname{Load}(L, t)}-P_{N S D(L, t)}\right) \\
& \left.\left.\left.+\sum_{V=1}^{N_{V}}\left(P_{C h(V, t)}-P_{D c h(V, t)}\right)\right)\right)+P F \times \sum_{t=1}^{T} \sum_{D G=1}^{N_{D G}}\left(P_{P G C(D G, t)}\right)+\sum_{L=1}^{N_{L}}\left(P_{N S D(L, t)}\right)\right)
\end{aligned}
$$

Maximum and minimum functions are also non-convex functions. However, it is possible to remove the non-convexity of function $f_{2}$ turning the optimization problem into a mixed-integer linear programming problem, considering the introduction of two epigraph variables that will eliminate the non-convexity in Eq. (18). In this away, epigraph variables maxLoad and minLoad are introduced in Eq. (19) to handle with the max and min expression, respectively.

$$
\begin{aligned}
\min f_{2}= & \text { maxLoad }- \text { minLoad } \\
& +P F \times \sum_{t=1}^{T}\left(\sum_{D G=1}^{N_{D G}}\left(P_{P G C(D G, t)}\right)+\sum_{L=1}^{N_{L}}\left(P_{N S D(L, t)}\right)\right)
\end{aligned}
$$


where

maxLoad Epigraph variable to handle with the maximum power demand

minLoad Epigraph variable to handle with the minimum power demand

The example of the use of epigraphs variables is illustrated in [37] and it helped turning a non-linear optimization problem into a linear optimization problem. The use of epigraph variables requires the use of new constraints (Eqs. (20) and (21)) to determine their values.

$\sum_{L=1}^{N_{L}}\left(P_{\operatorname{Load}(L, t)}-P_{N S D(L, t)}\right)+\sum_{V=1}^{N_{V}}\left(P_{C h(V, t)}-P_{D c h(V, t)}\right)$

$\leqslant \operatorname{maxLoad} ; \forall t \in\{1, \ldots, T\}$

$$
\begin{aligned}
& \sum_{L=1}^{N_{L}}\left(P_{\text {Load }(L, t)}-P_{N S D(L, t)}\right)+\sum_{V=1}^{N_{V}}\left(P_{C h(V, t)}-P_{D c h(V, t)}\right) \\
& \quad \geqslant \text { minLoad } ; \forall t \in\{1, \ldots, T\}
\end{aligned}
$$

In practice, in Eq. (20) it is imposed that epigraph variable maxload must be higher than the power demand in each period $t$, and in Eq. (21) epigraph variable minload must be lower than the power demand in each period $t$. Eqs. (20) and (21) are classified as linear functions, eliminating the non-convexity of function $f_{2}$. Despite the use of some adjustments in $f_{2}$ optimization function, the load factor is used to evaluate the performance of the proposed method.

\subsection{Multi-objective function}

A multi-objective function (22) is proposed considering the objectives referred above. Each objective function $f_{1}$ and $f_{2}$ is multiplied by one weight factor ( $\beta$ and $\delta$ ). These weight factors allow giving more or less importance to each objective. The sum of the

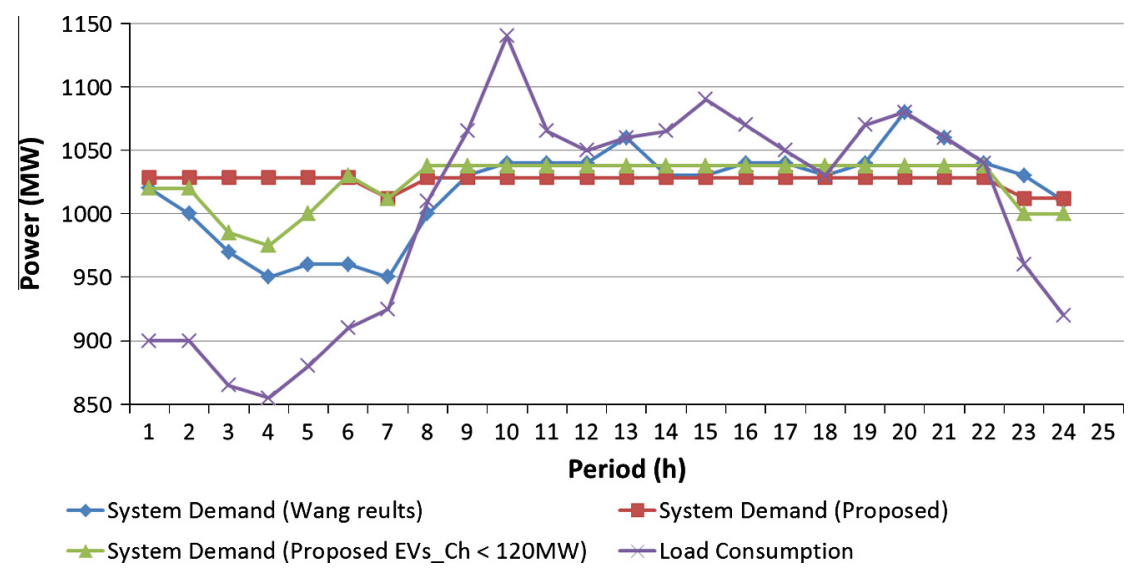

Fig. 1. Comparison of power demand curves.

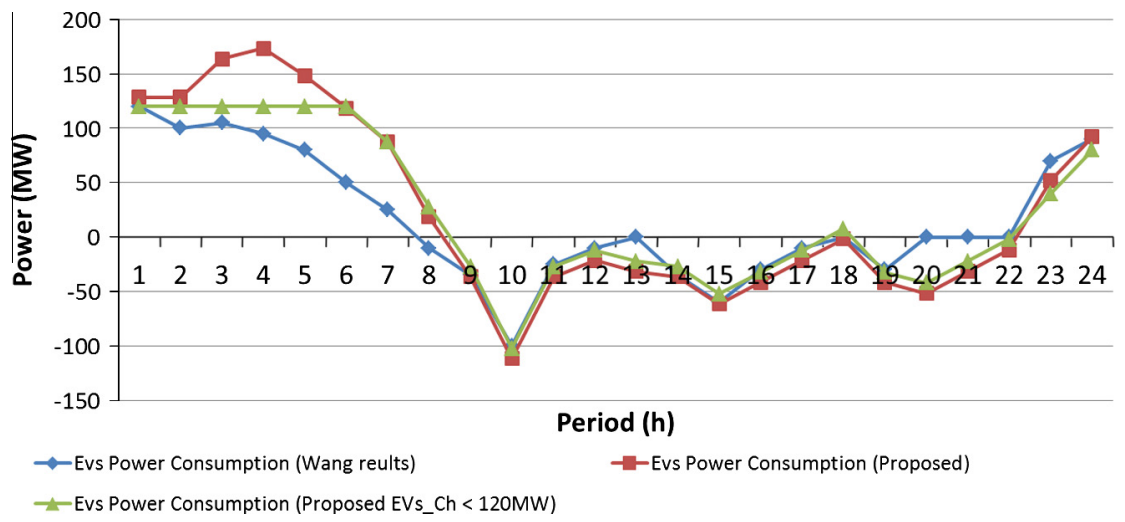

Fig. 2. Comparison of electric vehicles power consumption curves.

Table 1

\begin{tabular}{|c|c|c|c|c|}
\hline Subject & Before peak shaving & Wang results [15] & Proposed methodology & Proposed methodology (EVs_Ch < $120 \mathrm{MW}$ ) \\
\hline Peak value $(\mathrm{MW}) P_{p}$ & 1140 & 1080 & 1028.41 & 975.00 \\
\hline Valley value (MW) $P_{v}$ & 855 & 950 & 1012.11 & 1037.78 \\
\hline Peak value and valley difference (MW) $P_{d}$ & 285 & 130 & 16.30 & 62.78 \\
\hline Proportion $(\%) P_{d} / P_{p}$ & 25.00 & 12.04 & 1.59 & 6.05 \\
\hline Proportion (\%) $P_{d} / P_{v}$ & 33.33 & 13.68 & 1.61 & 6.44 \\
\hline
\end{tabular}

Comparison of the peak and valley power values considering different methodologies. 


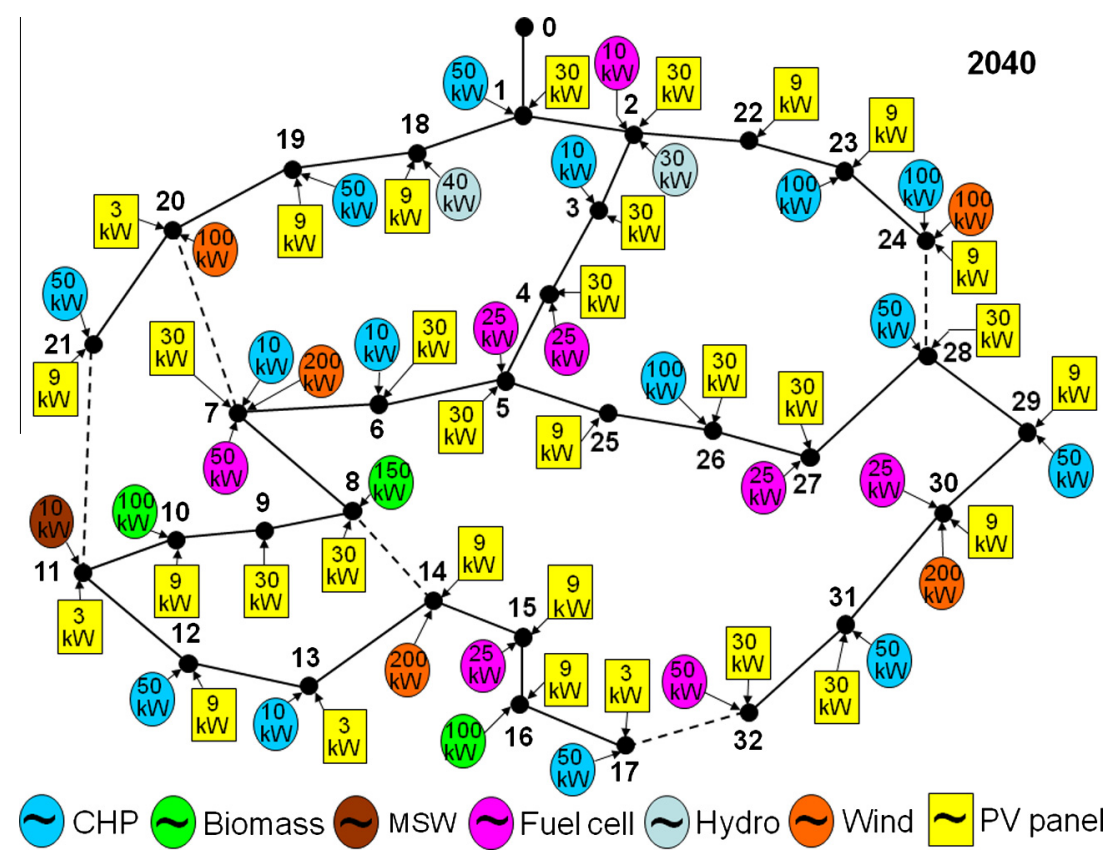

Fig. 3. 32-Bus distribution network [38].

Table 2

Generation profile information.

\begin{tabular}{|c|c|c|c|c|c|}
\hline \multirow[t]{2}{*}{ Technology } & \multirow[t]{2}{*}{ Number of units } & \multirow[t]{2}{*}{ Total installed power (kW) } & \multicolumn{3}{|c|}{ Cost scheme (m.u./kW h) } \\
\hline & & & Maximum & Mean & Minimum \\
\hline Photovoltaic (with "take-or-pay" contracts) & 32 & 1320 & 0.2540 & 0.1872 & 0.1100 \\
\hline Wind & 5 & 505 & 0.1360 & 0.0910 & 0.0600 \\
\hline Hydro small & 2 & 80 & 0.1450 & 0.1170 & 0.0890 \\
\hline Biomass & 3 & 350 & 0.2260 & 0.2007 & 0.1860 \\
\hline Waste to energy & 1 & 10 & - & 0.0560 & - \\
\hline Cogeneration & 15 & 725 & 0.1050 & 0.0753 & 0.0570 \\
\hline Fuel cell & 8 & 440 & 0.2000 & 0.0550 & 0.0100 \\
\hline External suppliers & 10 & $4200(\mathrm{kVA})$ & 0.1500 & 0.1050 & 0.0600 \\
\hline
\end{tabular}

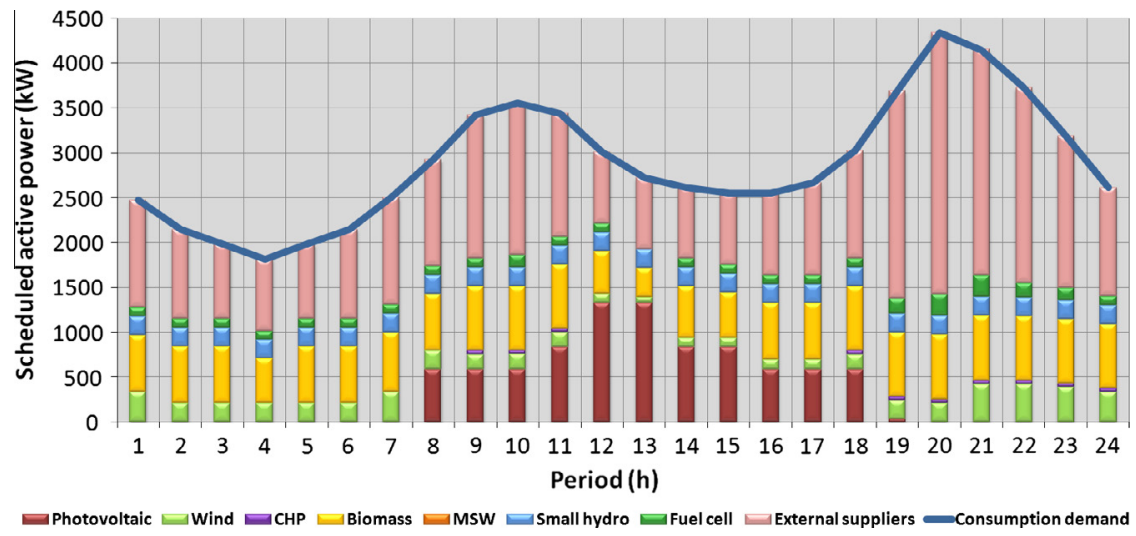

Fig. 4. Energy resources scheduling without EVs.

two weight factors must be equal to 1 . However, the objective function $f_{1}$ is expressed in monetary units, and the objective function $f_{2}$ is expressed in $\mathrm{kW}$. For leveling purposes, the function $f_{1}$ used an additional factor $S F$. This factor can be determined based on the inverse of the average energy price, multiplied by the number of periods (Example: $S F=240$ for an average energy price of $0.10 \mathrm{~m} . \mathrm{u} . / \mathrm{kW}$, considering 24 periods).

$\min f=\beta \times f_{1} \times S F+\delta \times f_{2}$

$\beta+\delta=1$ 
where

\begin{tabular}{ll}
\hline$f$ & Multi-objective function \\
$\beta$ & Function $f_{1}$ weight \\
$\delta$ & Function $f_{2}$ weight \\
$S F$ & Standard factor \\
\hline
\end{tabular}

\section{Case study}

In order to evaluate the performance of the proposed methodology, two case studies were developed. The first one intends to evaluate the proposed methodology, comparing it with the proposed by Zhenpo and Shuo in [15]. The second case study intends to evaluate the performance of the proposed methodology in situations with large amount of distributed generation, and to evaluate the use of different weights in the multi-objective function, namely for the operation cost, and load factor objective functions.

\subsection{Case Study 1 - Proposed methodology comparison}

In Zhenpo and Shuo [15] it is proposed a methodology to grid power peak shaving considering the use of electric vehicles with gridable capability. The proposed methodology considers the centralized control of electric vehicles charge and discharge using a decision-making process based on several aspects such as the data exchange, which includes EV charging time, charging capacity, power demand, and number of EVs connected to the grid. The case study presented in [15] considers three types of EVs, namely 2000 passenger cars, 600 municipal trucks, and 1000 public traffic vehicles. The EVs trips are not shown. However, it is possible to determine the trips energy consumption based on the differences between the charged and discharged energy. In [15], the EVs energy balance is indicated for blocks of hours $(0: 00-6: 00 ; 6: 00-$ $8: 00 ; 8: 00-17: 00 ; 17: 00-19: 00 ; 19: 00-24: 00)$. In the proposed methodology the balance is made for each hour.

Figs. 1 and 2, and Table 1 show the comparison between the methodology proposed in [15] and the methodology proposed in this paper. In [15], a max power value of the grid supply is imposed (120 MW). This constraint is not consensual because the network has enough capacity to supply more energy than this limit. However, two scenarios were simulated. In the first one (identified as "Proposed" in graphics and table), the EVs can charge energy without any network constraint. In the second scenario (identified as "Proposed EVsCh < $120 \mathrm{MW}$ " in graphics and table), a EVs charge constraint was included in order to avoid different assumptions between the compared methodologies.

Comparing the results presented in Figs. 1 and 2, and in Table 1, it is possible to verify the differences between the results obtained using the methodology proposed in [15], and the methodology proposed in the present paper. Even considering the limit in the EVs charge, the methodology proposed in the present paper enables the proportion $(P d / P p)$ to decreases from $12.04 \%$ to $6.05 \%$, and the proportion ( $P d / P v)$ to decrease from $13.68 \%$ to $6.44 \%$. Considering these values, it is possible to verify the effectiveness of the proposed methodology.
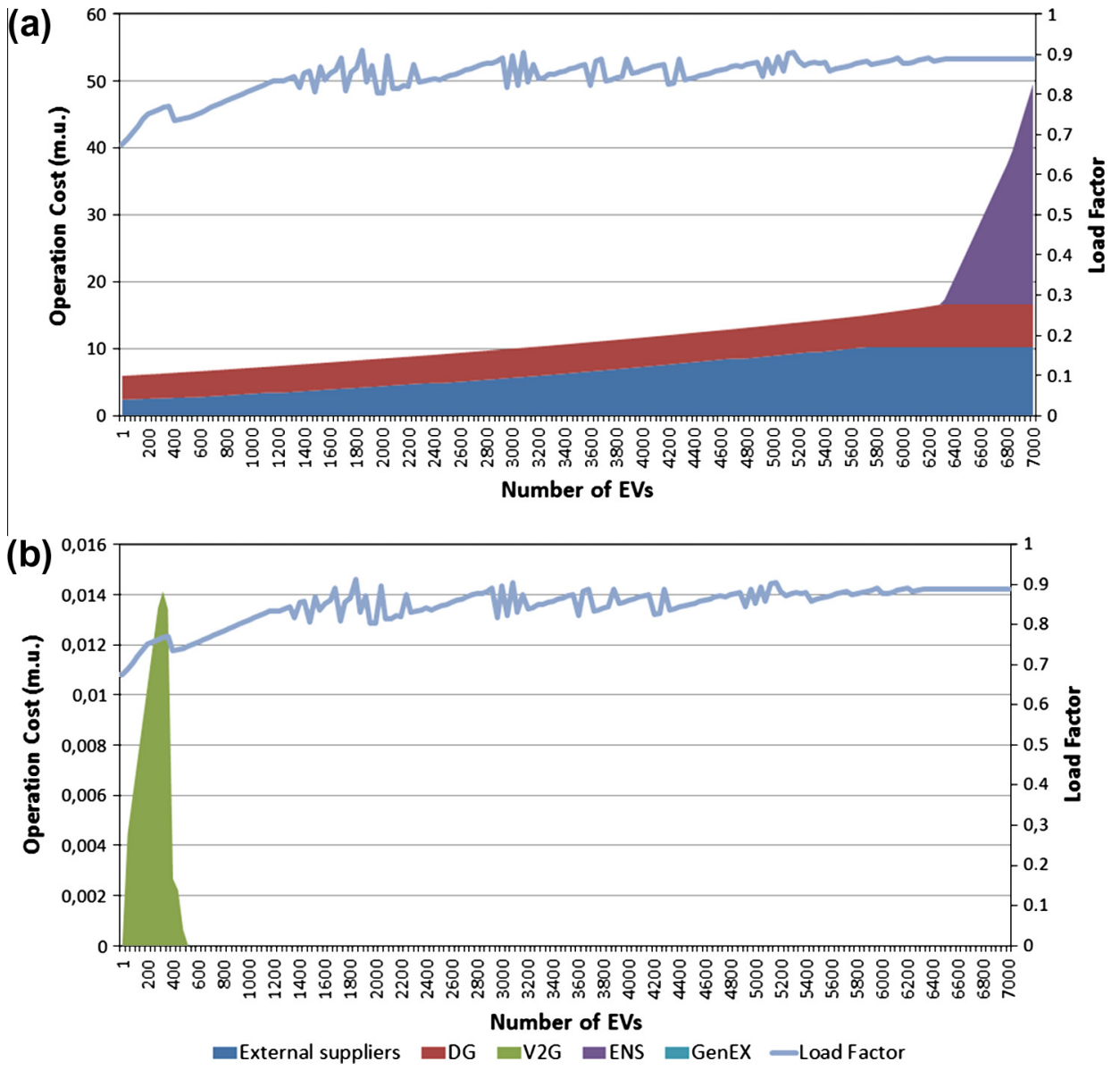

Fig. 5. Energy resources scheduling costs and load factor in simulation $1(\beta=1 ; \delta=0)$ : (a) General overview and (b) EVs focus. 


\subsection{Case Study 2 - 32-bus distribution network}

The 32-bus distribution network with high penetration of Distributed Generation (DG) [38] has been used to evaluate the impact of electric vehicles with V2G capacity. The proposed methodology is used considering a progressive increase of $\mathrm{EV}$ penetration from $1 \mathrm{EV}$ to $7000 \mathrm{EVs}$. A step of $40 \mathrm{EVs}$ is used to increase the EV's penetration. The values of the operation cost and of the load factor (used to verify the quality of the power demand curve) are analyzed for each simulation. Regarding the multi-objective function, five different values are considered to the $\beta$ and $\delta$ for each objective function.

\subsection{Operation scenario}

The 32-bus distribution network is shown in Fig. 3. DG units are represented with different colors depending on the type of technology used in each DG unit.

Table 2 presents the information of several generators implemented in the distribution network. In the table are indicated the number of units, the total installed power and the cost of each technology resource. The imported power of external suppliers is limited by the power cable capacity to 4.2 MVA.

Two-hundred and eighteen consumers are considered in the distribution network and the respective load demand diagram is

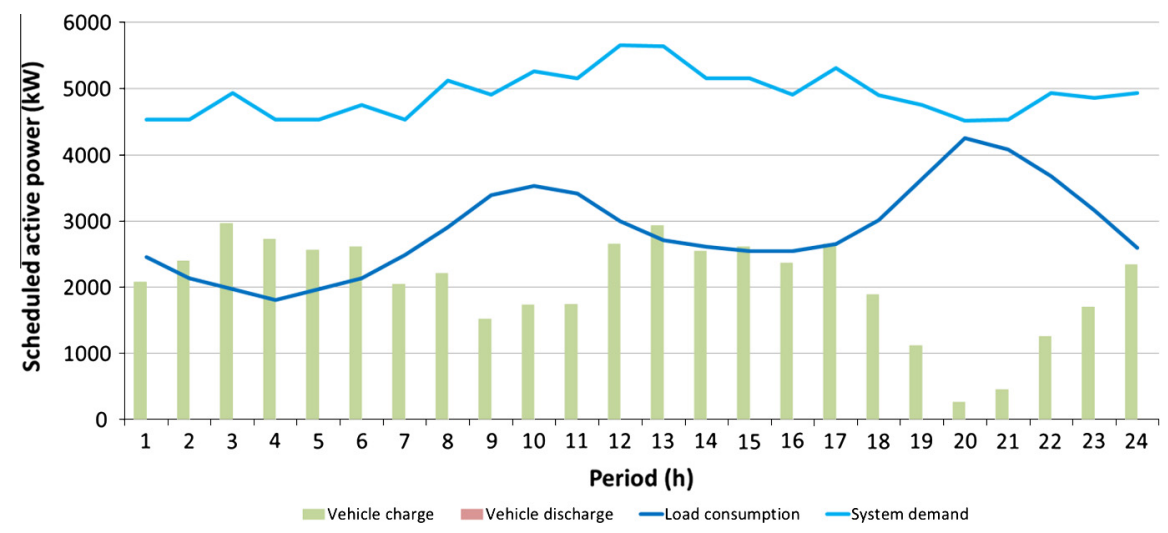

Fig. 6. Power demand curve in simulation 1 considering 3500 EVs.
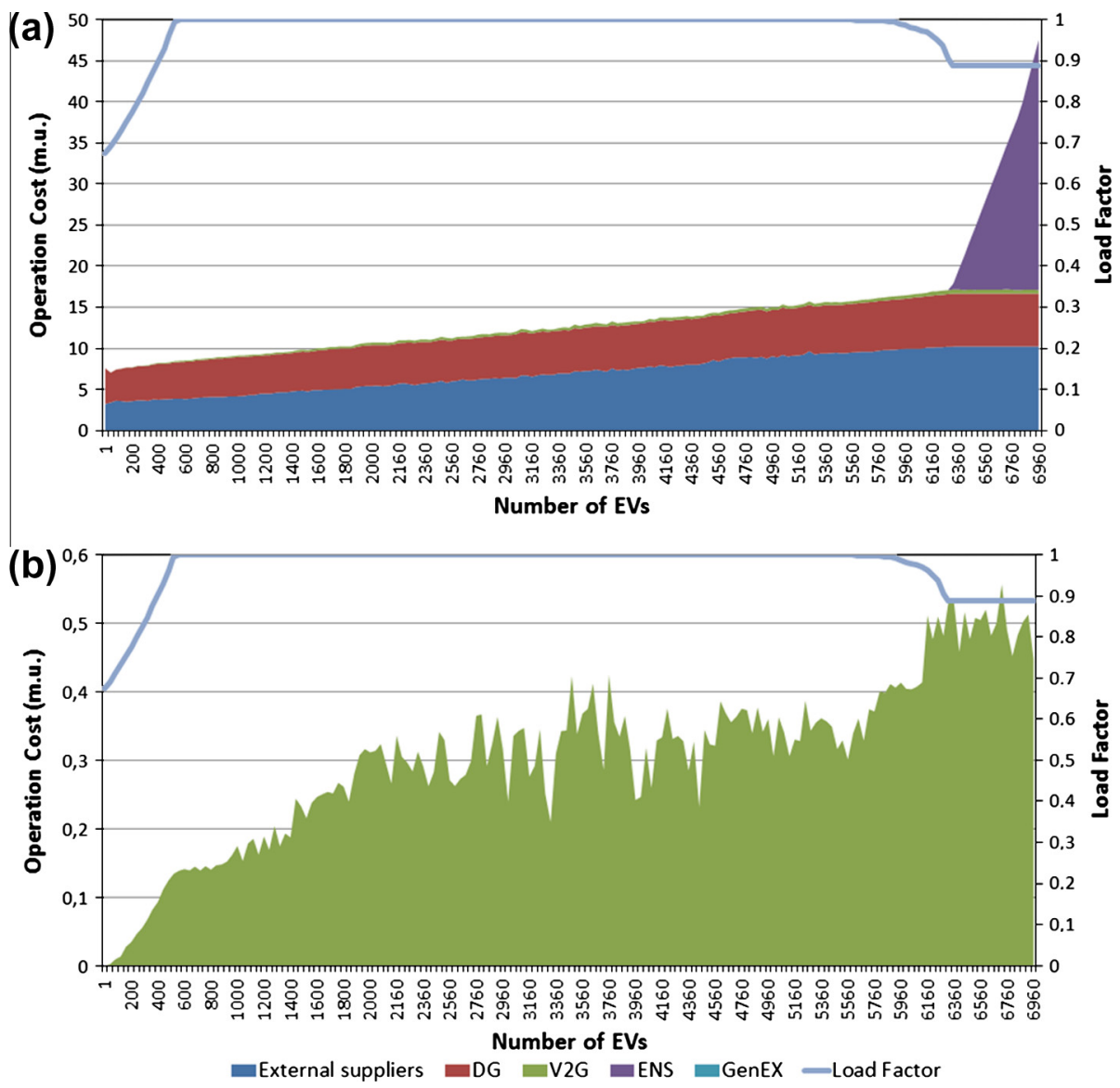

Fig. 7. Energy resources scheduling costs and load factor in simulation $2(\beta=0 ; \delta=1)$ : (a) General overview and (b) EVs focus. 


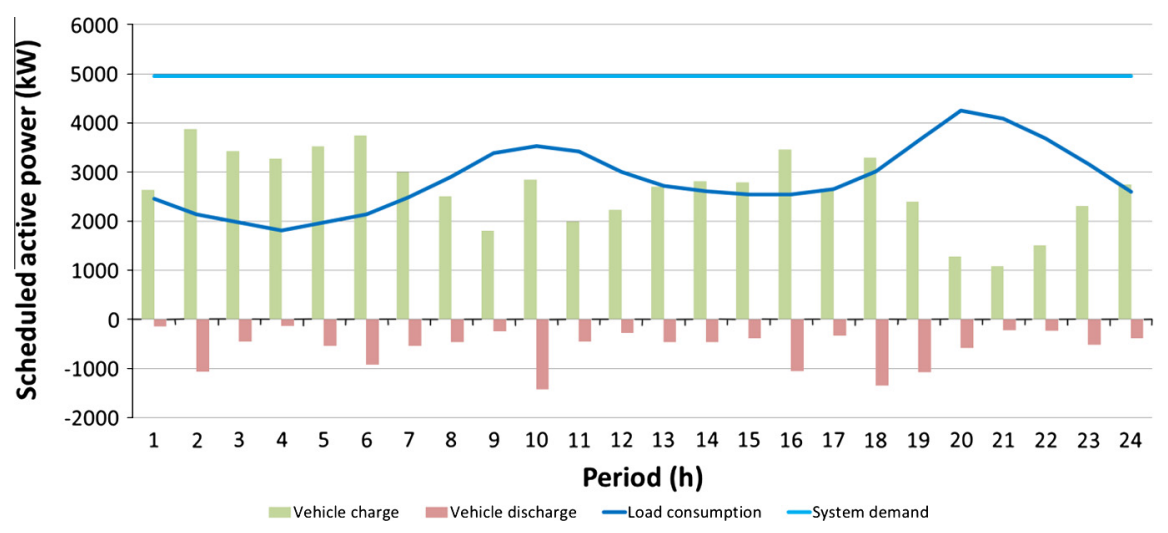

Fig. 8. Power demand curve in simulation 2 considering 3500 EVs.

Table 3

Performance of the execution time of the power demand curve optimization.

\begin{tabular}{|c|c|c|c|c|c|c|}
\hline \multirow{2}{*}{$\begin{array}{l}\text { EVs } \\
\text { number }\end{array}$} & \multicolumn{2}{|l|}{ Execution time $(\mathrm{s})$} & \multicolumn{2}{|c|}{ Operation cost (m.u.) } & \multicolumn{2}{|l|}{ Load factor } \\
\hline & $\begin{array}{l}\text { Without epigraph } \\
\text { variables }\end{array}$ & $\begin{array}{l}\text { With epigraph } \\
\text { variables }\end{array}$ & $\begin{array}{l}\text { Without epigraph } \\
\text { variables }\end{array}$ & $\begin{array}{l}\text { With epigraph } \\
\text { variables }\end{array}$ & $\begin{array}{l}\text { Without epigraph } \\
\text { variables }\end{array}$ & $\begin{array}{l}\text { With epigraph } \\
\text { variables }\end{array}$ \\
\hline 1 & 3.0830 & 0.4662 & 7.570 & 7.566 & 0.673 & 0.674 \\
\hline 1000 & $1142.0(19 \mathrm{~min})$ & 8.3012 & 8.889 & 9.132 & 0.756 & 1 \\
\hline 2000 & 7082.7 (2 h) & 20.0947 & 10.258 & 10.708 & 0.802 & 1 \\
\hline 3000 & $21,846(6 \mathrm{~h})$ & 31.0370 & 11.603 & 11.876 & 0.778 & 1 \\
\hline 4000 & $92,191(25 \mathrm{~h})$ & 44.7714 & 13.175 & 13.322 & 0.820 & 1 \\
\hline 5000 & $236,810(65 \mathrm{~h})$ & 58.8630 & 14.673 & 14.987 & 0.829 & 1 \\
\hline 6000 & $402,820(111 \mathrm{~h})$ & 78.6121 & 16.158 & 16.533 & 0.863 & 0.983 \\
\hline 7000 & $635,670(176 \mathrm{~h})$ & 112.1425 & 63.243 & 50.149 & 0.871 & 0.887 \\
\hline
\end{tabular}

(a)

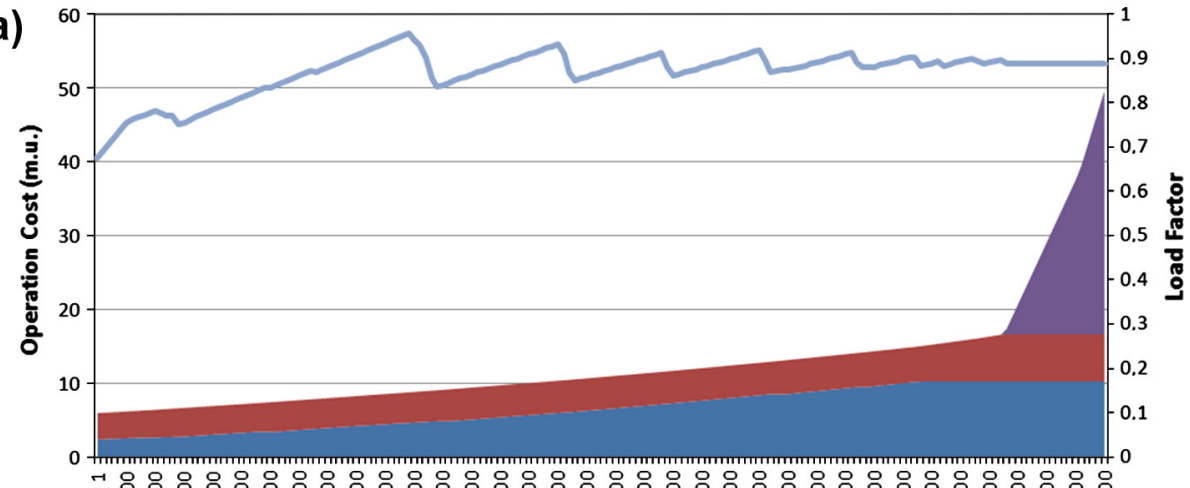

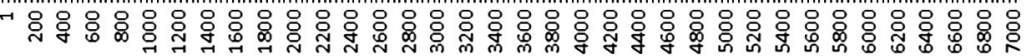
Number of EVs

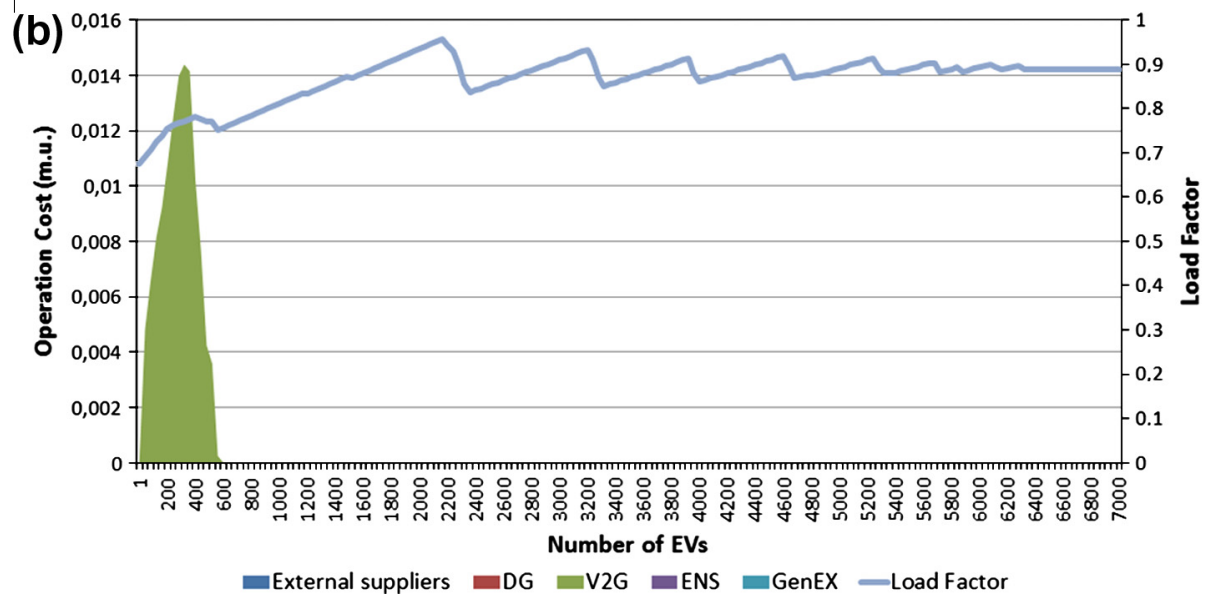

Fig. 9. Energy resources scheduling costs and load factor in simulation 3 ( $\beta=0.75 ; \delta=0.25$ ): (a) General overview and (b) EVs focus. 
shown in Fig. 4 [38]. The load factor of the presented network is 0.6732 and the operation cost, considering only the use of external suppliers energy and the distributed generation is of 5954.33 m.u. This value was obtained using the proposed method considering the objective function $f_{1}$ to minimize the operation cost. In Fig. 4 is presented the obtained resources scheduling.

This simulation considers $4 \mathrm{EV}$ users' profiles to evaluate the impact of EVs in the distribution network, with different driving patterns and minimum trip requirements (Eq. (8)). These profiles were based on a MERGE report published in 2010 [39]. The initial state of EVs batteries (energy stored) is randomly determined for each EV. It is imposed for the present case-study that at the end of period 24 (the last one), the state of charge of each vehicle battery must be, at least $30 \%$ of battery capacity in order to avoid problems in the following day.

The proposed methodology has been implemented in GAMS, and the Matrix Laboratory (MATLAB) has been used for programming the interface. The case study has been tested on a PC with two processors Intel ${ }^{\circledR}$ Xeon $^{\circledR}$ X5450 $3 \mathrm{GHz}$, each one with four Cores, 4 GB of random-access-memory (RAM) and Windows Server 2008, 32 bits.

\subsection{Simulation 1 - Operation cost optimization $(\beta=1 ; \delta=0)$}

In the first simulation, it is only considered the objective function $f 1$. In this simulation, the minimum operation cost for each considered EVs penetration (since 1-7000 EVs) is determined. Fig. 5 shows the energy cost concerning each scheduled resource type, and the resulting load factor. In order to evaluate the cost with the EVs discharge, Fig. 5 is divided into two parts: the first one (a)) shows a general overview of the cost by energy resource; the second one (b)) shows the costs for the VPP to remunerate the EVs discharge. A distinct scale is used for a better evaluation of this resource results.

By analyzing Fig. 5, it is possible to verify that the system operation costs increases along with the EVs. After $6300 \mathrm{EVs}$, the system has not enough generation resources to support all the system demand, which results in the use of Non-Supplied Demand (NSD) and, consequently, the system operation costs increase significantly. According to [40], considering the information from 2009 , the NSD costs for utilities or aggregators can change between $0.65 \mathrm{USD} / \mathrm{kW}$ h for domestic users to $4 \mathrm{USD} / \mathrm{kW}$ h for the industrial ones. In the present simulation, the NSD cost varies between 2 and 4 m.u./kW h.

The load factor does not have a regular evolution considering EVs penetration increasing, as it is shown in Fig. 5. However, it is always better than the scenario without EVs. EVs discharge has a small impact in the operation management cost. In fact, the EVs discharge cost depends on the EVs charge cost $\left(c_{D \operatorname{ch}(V, t)}=0.07+-\right.$ $\left.c_{C h(V, t)}\right)$. The value $0.07 \mathrm{~m} . \mathrm{u} / \mathrm{kW}$ h was obtained based on the degradation cost $(0.042 \mathrm{~m} . \mathrm{u} / \mathrm{kW} \mathrm{h})$ proposed in [32], plus a profit, and the EVs charge costs depends on the available generation costs or the external suppliers energy costs. EVs only discharge energy to the distribution network when the penetration is lower than 560 EVs. In these scenarios, EVs can be charged in off-peak hours using the generation units with lower generation costs, and afterwards, discharge energy to the grid in peak periods at competitive prices. With the increasing number of EVs, more energy is necessary during the off-peak periods to charge the EVs batteries, and it is consequently necessary to use more expensive generation
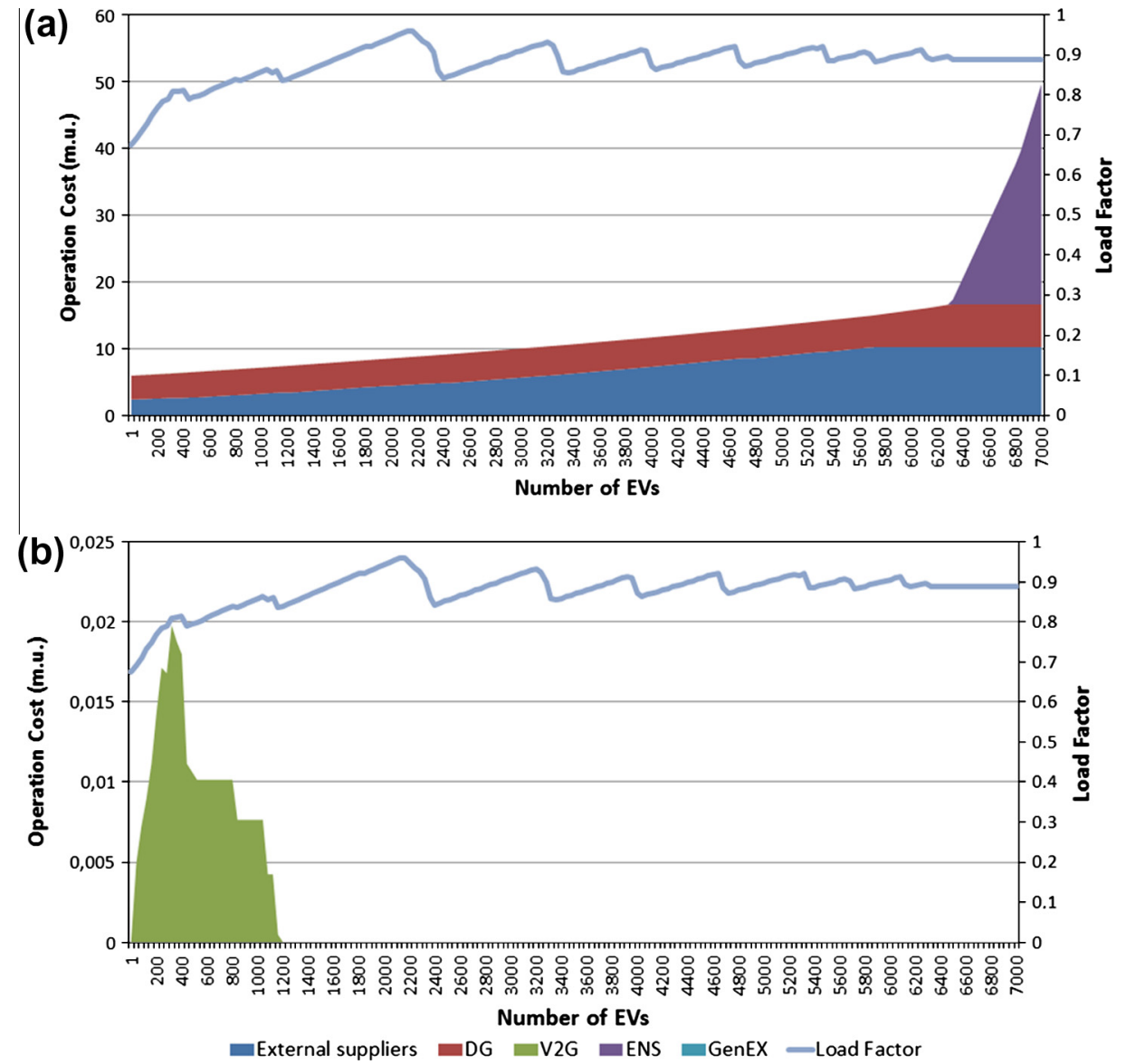

Fig. 10. Energy resources scheduling costs and load factor in simulation 4 ( $\beta=0.50 ; \delta=0.50)$ : (a) General overview and (b) EVs Focus. 

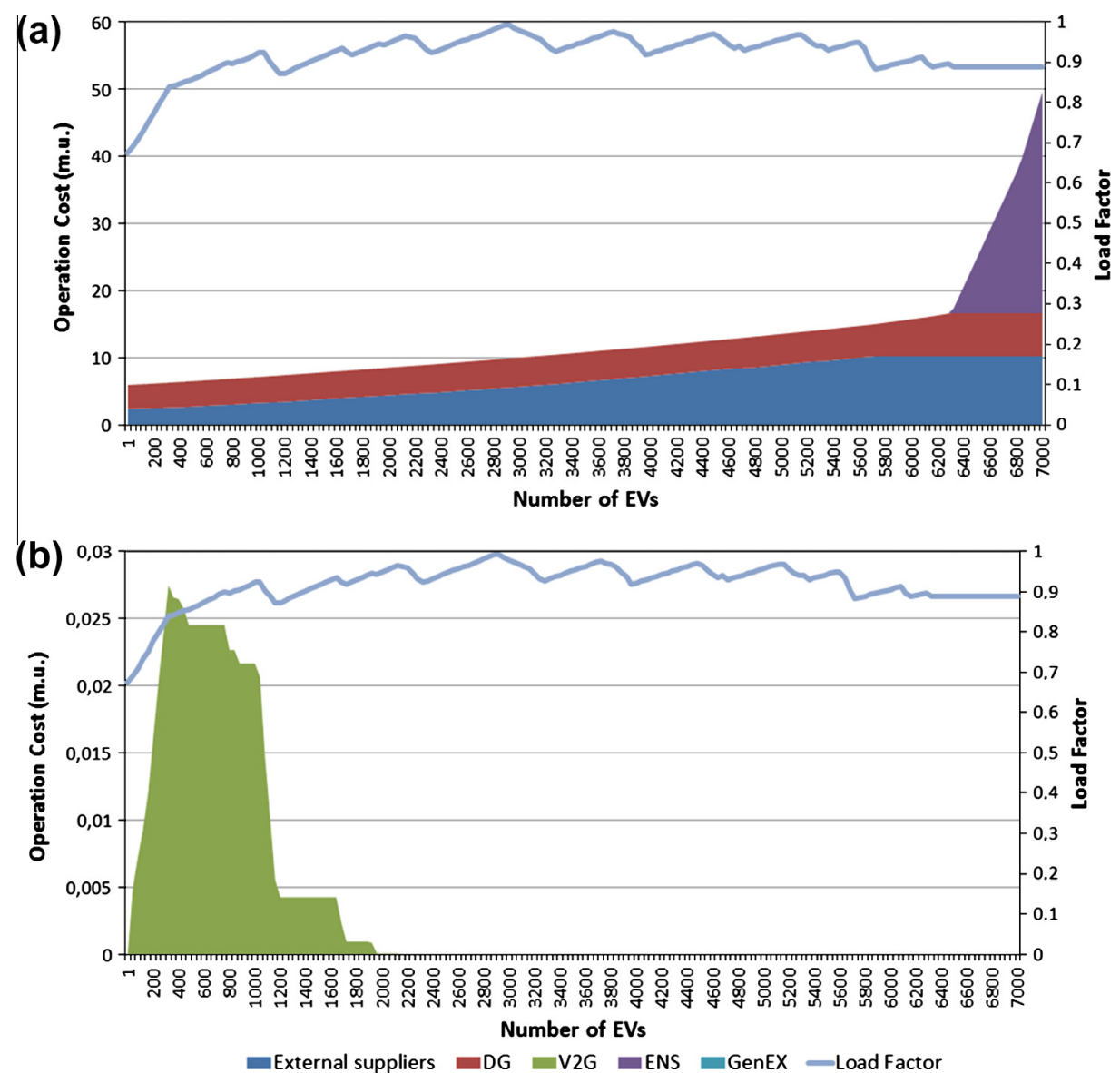

Fig. 11. Energy resources scheduling costs and load factor in simulation $5(\beta=0.25 ; \delta=0.75)$ : (a) General overview and (b) EVs focus.

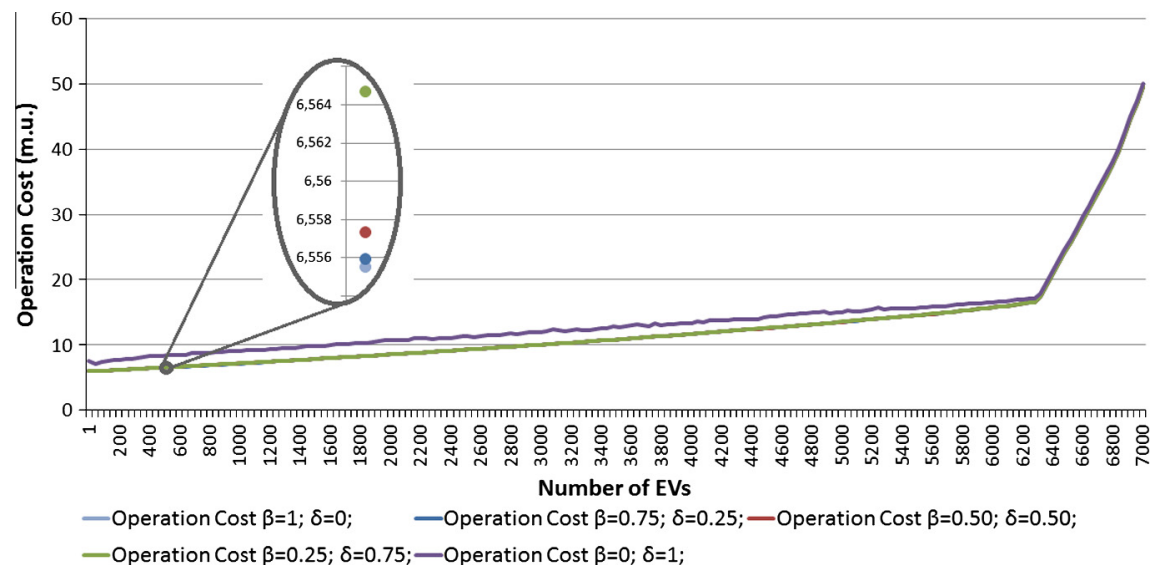

Fig. 12. Comparison of operation cost simulations.

units in the referred period, leading to an increase in the average EVs charge cost.

An example of power demand curve for the scenario with 3500 EVs can be seen in Fig. 6. The system demand, presented in Fig. 6, considers the load consumption and the EVs charge. It is clear that the intelligent use of EVs charge power helps reducing the load variation. The power demand curve optimization makes an intensive use of EVs charge in hours with low load demand. However, the system peak increases significantly and it occurs in hours 12 and 13, because of high generation of photovoltaic units.
4.5. Simulation 2 - Power demand curve optimization $(\beta=0 ; \delta=1)$

In the second simulation, the power demand curve optimization $f_{2}$ is considered. In Fig. 7 are presented the obtained results for several EVs penetration scenarios.

As expected, the values of the load factor are higher than in simulation 1 (see Section 4.3). In this simulation the value of load factor tends to 1 . With more than $520 \mathrm{EVs}$ the value of the Load factor is 1 . However, with more than $5500 \mathrm{EVs}$ the value of the load factor drops to 0.89 . The load factor decreases because a large amount of 
EVs are disconnected to the network in some hours, and consequently it is impossible to adjust the consumption in these hours. After $6300 \mathrm{EVs}$ the load factor value decreases to 0.89 due to the NSD and consequently there is a reduction of the minimum load. The system operation cost is higher in simulation 2; however, it increases with EVs penetration. The use of EVs discharge is not regular and it does not depend on the number of EVs in the system.

The resulting power demand curve for the scenario with 3500 EVs can be seen in Fig. 8. The system demand presented in Fig. 8 represents the consumer's consumption, plus the consumption corresponding to EVs battery charging, and the subtraction of generation corresponding EVs battery discharge. It is clear that the intelligent use of EVs charge and discharge power helps reducing the load variation and maximizing the load factor. Other important aspect in this simulation is the significant reduction of the peak demand.

It is important to show the improvement in terms of execution time that the epigraph variables maxLoad and minLoad introduced in the power demand curve optimization. In this sub-section the results of the execution time in the power demand curve optimization are presented, with and without epigraph variables. The power demand curve optimization without epigraph variables uses the objective function presented in Eq. (17) and the constraints in Eqs. (1)-(13). This optimization problem is classified as a mixedinteger non-linear programming problem, because the max and $\min$ functions used in the objective function are non-convex. The power demand curve optimization with epigraph variables uses the objective function presented in Eq. (18) and the constraints in Eqs. (1)-(13), (19) and (20). Table 3 shows the execution time in seconds for both optimization problems.

The results of the execution time shown in Table 3 proved that the epigraph variables contribute to the improvement of the power demand curve optimization. The epigraph variables eliminated a non-convexity introduced in Eq. (17) by the max and min functions, but they have also improved the execution time of the optimization problem. In the scenario with $7000 \mathrm{EVs}$, the optimization problem without epigraph variables presented an execution time of $635,670 \mathrm{~s}$, and the same problem with epigraph variables presented a execution time of $50.149 \mathrm{~s}$.

\subsection{Simulation 3-5 - Multi-objective function $(\beta \in] 0,1[; \delta \in] 0,1[)$}

In this section the results to multi-objective simulations considering three different weights are presented (simulation 3 $\beta=0.75 ; \delta=0.25$; simulation $4-\beta=0.50 ; \delta=0.50$; simulation $5-\beta=0.25 ; \delta=0.75$ ). In the present simulation, the average energy price is about 0.20 m.u./kW h, resulting in a $S F$ value equal to 120 . Figs. 9-11 show the results obtained for simulations 3-5, respectively. Fig. 12 shows the comparison of operation costs, and Fig. 13 shows the operation cost relation in percentage between simulations 2-5 with simulation 1 (simulation with lower operation cost). In the same way, Fig. 14 shows the comparison of load factors, and Fig. 15 shows the load factor relation in percentage between simulations 2-5 with simulation 1 (simulation with lower load factor).

By analyzing Figs. 9-15, it is possible to see the impact of the multi-objective function in the load factor. However, in the operation cost the impact is low mainly when the multi-objective functions are used. In simulation 2, the operation cost is about $20 \%$ higher than in simulation 1, but in simulation 4 the operation cost is only $0.03 \%$ higher than in simulation 1 . By comparing the average load factor values in these simulations, the following values were obtained: 0.842 in simulation $1,0.982$ in simulation 2 , and 0.878 in simulation 4 . In practice, it is possible to improve the load factor in $5 \%$ with an increase of only $0.03 \%$ in the operation cost.

In Figs. 12 and 13 it is possible to compare the operation cost in absolute and relative values, respectively. The differences between the operation costs in simulation 1 and in simulations 2, 3 and 4 are marginal; the maximum operation cost variation is $0.15 \%$. In Fig. 12 the operation costs differences are imperceptive for simulations 1, 3-5 (the curves are overlapped). The differences are more perceptive in Fig. 13 in relative comparison. This situation occurs because of the high cost of EVs discharge. In practice, the methodology tries to optimize the load factor generating a better EVs charge scheduling, using the discharge only in most critical hours. In Figs. 9-11 it is possible to evaluate the EVs discharge. In simulation 3 (Fig. 9), the methodology only considers the use of EVs discharge in cases with less than 600 EVs. In simulation 5 (Fig. 11), the methodology considers the use of EVs until a penetration of 2000 EVs.

Regarding the load factor, Figs. 14 and 15 show the differences obtained in each simulation. In this case, the differences are significant with variations up to $34 \%$. Other important aspect is the load factor variation for different EVs penetration in each simulation. In simulation 2 the load factor is practically immune to EVs penetration, except in the case with very few EVs (less than 560), and very high number (more than 5500) of EVs. On the other hand, in simulation 1 the load factor changes significantly for different EVs penetration.

Considering the comments, it is possible to conclude the adequacy of the proposed method in the distributed energy resources management.

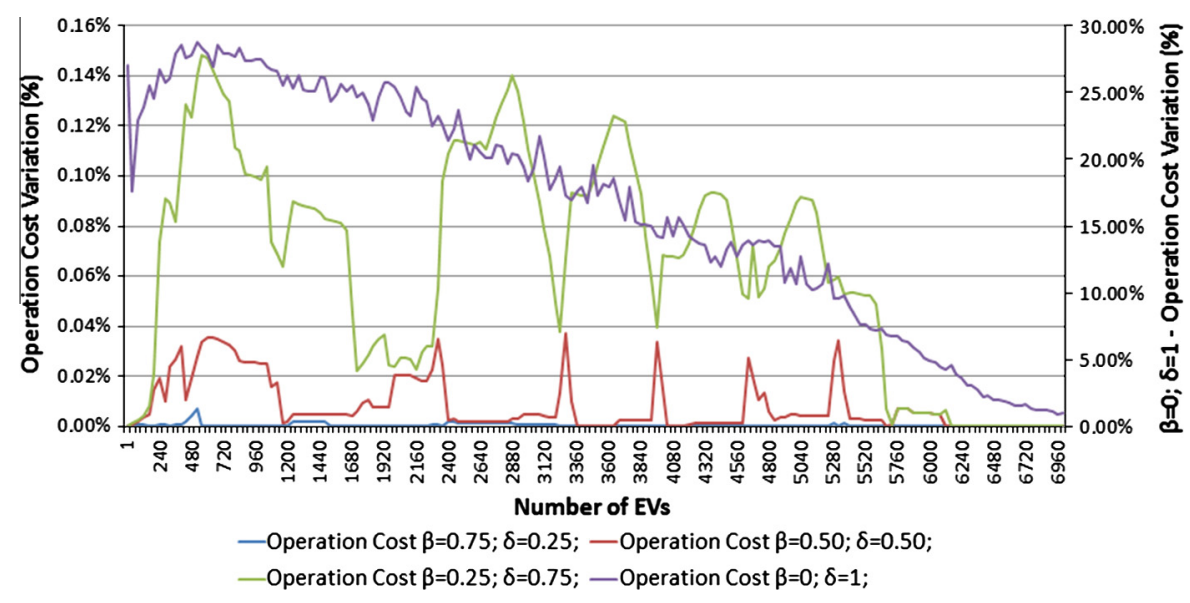

Fig. 13. Comparison of the operation cost variation. 


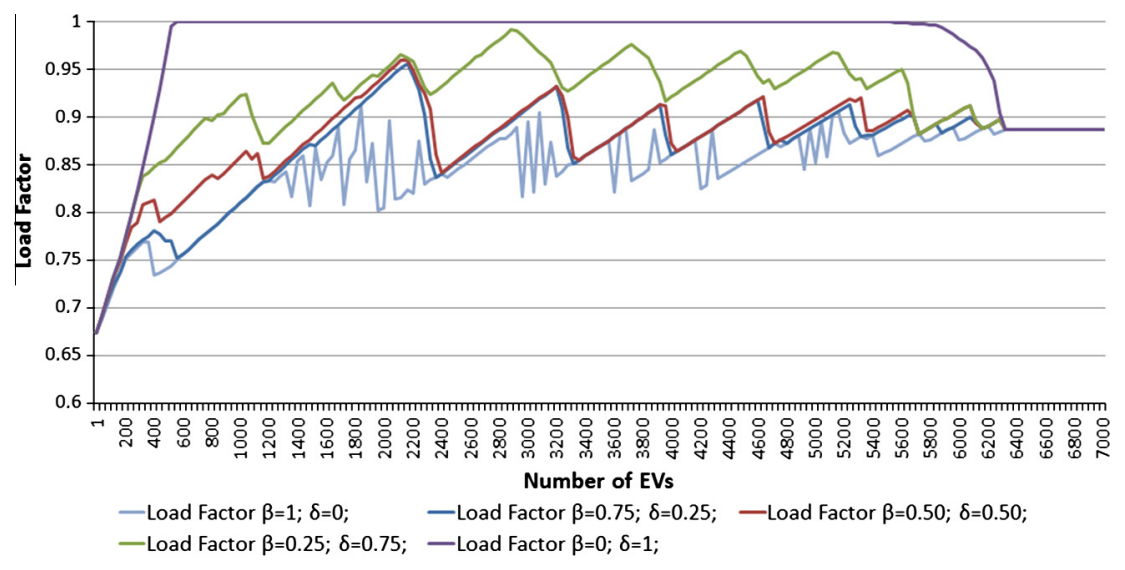

Fig. 14. Comparison of load factor simulations.

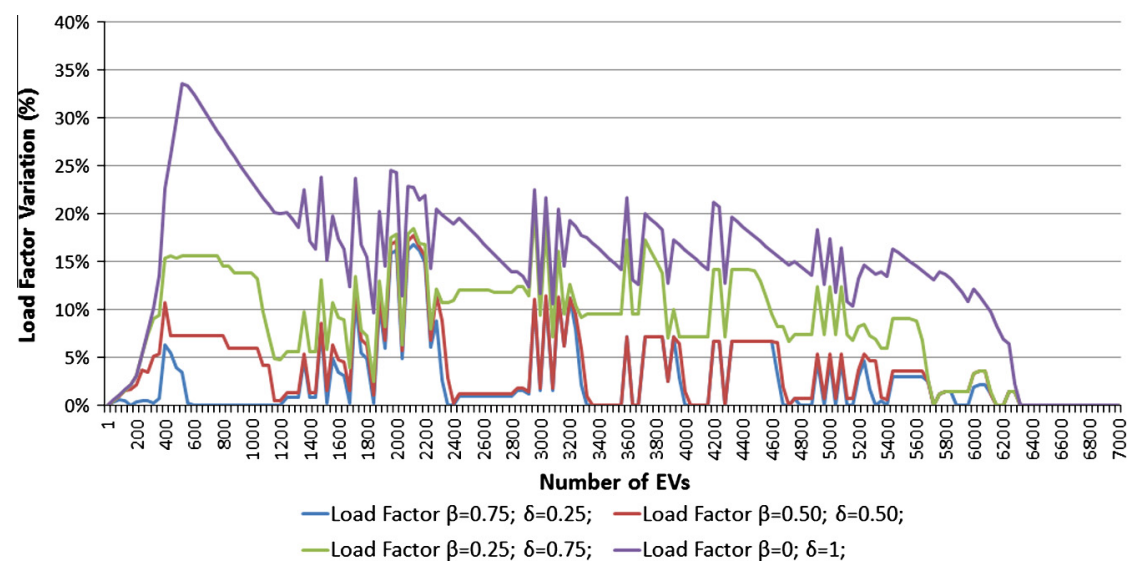

Fig. 15. Comparison of the load factor variation.

\section{Conclusions}

Smart grids with an intensive use of distributed energy resources will play a major role in future power systems. The massive use of electric vehicles, namely the ones with gridable capabilities (usually referred as vehicle-to-grid or V2G) should also be considered.

This paper presents two perspectives of managing efficiently these resources, considering the number of electric vehicles that can be connected to a specific distribution network. EVs charge and discharge are jointly managed with other available resources, considering two different objectives. These include the minimization of operation costs, and the optimization of the power demand curve. The paper includes a case study considering a 32-bus network with intensive use of distributed resources. The power demand curve optimization considers several EVs penetration levels, and with $700 \mathrm{EVs}$ it is possible to obtain a load factor close to 1 . The VPP will benefit from this kind of power demand curve management that allows achieving an almost constant system demand, helping the resources' scheduling for the next day. The results presented in the paper clearly show that an efficient management of future smart grids with massive use of EVs requires undertaking adequate optimizations considering several objective functions and taking into account considering all the relevant technical constraints. The results show that the optimal solution of the considered objective functions cannot be simultaneously obtained. However, it is possible to verify that a small increase in the operation cost makes it possible to significantly improve the load factor. As an example, the load factor can increase $5 \%$ with an increase of only $0.03 \%$ in the operation cost. Other important conclusion of this paper is that the management of EVs charge is even more important than the management of the EVs discharge, in order to improve the load factor without significantly increasing the operation costs. Although the presented results cannot be generalized for distribution networks with different characteristics, the proposed methodology is of general application and realistic enough to reach valuable conclusions about the adequate management in each specific case.

\section{Acknowledgements}

This work is supported by FEDER Funds through COMPETE program and by National Funds through FCT under the Projects FCOMP-01-0124-FEDER: PEst-OE/EEI/UI0760/2011, PEst-OE/EEI/ UI0760/2014, and PTDC/SEN-ENR/122174/2010. The first author is also supported by funding from The Danish Council for Strategic Research under grant agreement no. 11-116794.

\section{References}

[1] Wissner M. The smart grid - a saucerful of secrets? Appl Energy 2011;88:2509-18.

[2] Vale Z, Morais H, Silva M, Ramos C. Towards a future SCADA. In: Power \& Energy Society General Meeting, 2009 PES ‘09 IEEE; 2009. p. 1-7. 
[3] Silva M, Morais H, Vale Z. An integrated approach for distributed energy resource short-term scheduling in smart grids considering realistic power system simulation. Energy Convers Manage 2012;64:273-88.

[4] Tina G, Ventura C. Simulation tool for energy management of photovoltaic systems in electric vehicles. Energy Convers Manage 2014;78:851-61.

[5] Faria P, Vale Z, Morais H. A real time pricing approach to deal with excessive wind power situations. European Wind Energy Association; 2012 [EWEA 2012].

[6] Morais H, Kádár P, Faria P, Vale ZA, Khodr HM. Optimal scheduling of a renewable micro-grid in an isolated load area using mixed-integer linear programming. Renew Energy 2010;35:151-6.

[7] Lightner E, Widergren S. An orderly transition to a transformed electricity system. IEEE Trans Smart Grid 2010;1:3-10.

[8] Sovacool B, Hirsh R. Beyond batteries: an examination of the benefits and barriers to plug-in hybrid electric vehicles (PHEVs) and a vehicleto-grid (V2G) transition. Energy Policy 2009;37:1095-103.

[9] Dinger A, Martin R, Xavier M, Maximilian R, Rizoulis D, Russo M, et al. Batteries for electric cars: challenges, opportunities, and the outlook to 2020. In: The Boston Consulting Group, 2010.

[10] Kerestes R, Reed G, Sparacino A. Economic analysis of grid level energy storage for the application of load leveling. In: IEEE power and energy society general meeting, 2012. pp. 1-9.

[11] Sousa T, Morais H, Vale Z, Faria P, Soares J. Intelligent energy resource management considering vehicle-to-grid: a simulated annealing approach. IEEE Trans Smart Grid 2012;3:535-42.

[12] Su W, Chow M-Y. Computational intelligence-based energy management for a large-scale PHEV/PEV enabled municipal parking deck. Appl Energy 2012;96:171-82.

[13] Sortomme E, Hindi M, MacPherson S, Venkata S. Coordinated charging of plugin hybrid electric vehicles to minimize distribution system losses. IEEE Trans Smart Grid 2011;2:198-205.

[14] Druitt J, Früh W-G. Simulation of demand management and grid balancing with electric vehicles. J Power Sour 2012;216:104-16.

[15] Zhenpo W, Shuo W. Grid power peak shaving and valley filling using vehicleto-grid systems. IEEE Trans Power Deliv 2013;28:1822-9.

[16] US Department of Transportation. Summary of travel trends: 2009 national household travel survey, 2011.

[17] Chan C. The state of the art of electric, hybrid, and fuel cell vehicles. Proc IEEE 2007;95:704-18.

[18] Ehsani M, Gao Y, Emadi A. Modern electric, hybrid electric, and fuel cell vehicles: fundamentals, theory, and design. CRC Press; 2009.

[19] Wu X, Cao B, Li X, Xu J, Ren X. Component sizing optimization of plug-in hybrid electric vehicles. Appl Energy 2011;88:799-804.

[20] Faria R, Moura P, Delgado J, de Almeida A. A sustainability assessment of electric vehicles as a personal mobility system. Energy Convers Manage 2012;61:19-30.

[21] He H, Xiong R, Guo H, Li S. Comparison study on the battery models used for the energy management of batteries in electric vehicles. Energy Convers Manage 2012;64:113-21.

[22] David Huang K, Tzeng S-C. A new parallel-type hybrid electric-vehicle. Appl Energy 2004;79:51-64.
[23] Chau KT, Wong YS. Overview of power management in hybrid electric vehicles. Energy Convers Manage 2002:43:1953-68.

[24] Srivastava A, Annabathina B, Kamalasadan S. The challenges and policy options for integrating plug-in hybrid electric vehicle into the electric grid. Electr 2010;23:83-91.

[25] Fernandes C, Frías P, Latorre J. Impact of vehicle-to-grid on power system operation costs: the Spanish case study. Appl Energy 2012;96:194-202.

[26] Green II R, Wang L, Alam M. The impact of plug-in hybrid electric vehicles on distribution networks: a review and outlook. Renew Sustain Energy Rev 2011;15:544-53.

[27] Sousa T, Morais H, Soares J, Vale Z. Day-ahead resource scheduling in smart grids considering vehicle-to-grid and network constraints. Appl Energy 2012;96:183-93.

[28] Zakariazadeh A, Jadid S, Siano P. Multi-objective scheduling of electric vehicles in smart distribution system. Energy Convers Manage 2014;79:43-53.

[29] Jian L, Zhu X, Shao Z, Niu S, Chan C. A scenario of vehicle-to-grid implementation and its double-layer optimal charging strategy for minimizing load variance within regional smart grids. Energy Convers Manage 2014;78:508-17.

[30] Fazelpour F, Vafaeipour M, Rahbari O, Rosen M. Intelligent optimization to integrate a plug-in hybrid electric vehicle smart parking lot with renewable energy resources and enhance grid characteristics. Energy Convers Manage 2014:77:250-61.

[31] Hong L, Huansheng N, Yan Z, Guizani M. Battery status-aware authentication scheme for V2G networks in smart grid. IEEE Trans Smart Grid 2013;4:99-110.

[32] Peterson S, Whitacre J, Apt J. The economics of using plug-in hybrid electric vehicle battery packs for grid storage. J Power Sour 2010;195:2377-84.

[33] Peterson S, Apt J, Whitacre J. Lithium-ion battery cell degradation resulting from realistic vehicle and vehicle-to-grid utilization. J Power Sour 2010;195:2385-92.

[34] Rosenthal R. GAMS - A User's Guide, March, 2014. Available at: http:/ www.gams.com/dd/docs/bigdocs/GAMSUsersGuide.pdf. Visited on February 2014.

[35] Rastler D. Electricity energy storage technology options - a white paper primer on applications, costs and benefits. Electric Power Research Institute; 2010.

[36] Salimi-Beni A, Fotuhi-Firuzabad M, Farrokhzad D, Alemohammad SJ. A new approach to determine base, intermediate and peak-demand in an electric power system. In: International conference on power system technology, PowerCon 2006, 2006. p. 1-5.

[37] Horst R, Pardalos P, Van Thoai N. Nonconvex optimization and its applications - introduction to global optimization. Springer; 2000.

[38] Faria P, Vale Z, Ferreira J. Demsi - a demand response simulator in the contex of intensive use of distributed generation. In: 2010 IEEE international conference on systems man and cybernetics (SMC), 2010. p. 2025-32.

[39] Ball R, Keers N, Alexander M, Bower E. Deliverable D2.1 modelling electric storage devices for EV. MERGE Project EU: United Kingdom; 2010.

[40] Vasquez P, Vaca A. Methodology for estimating the cost of energy not supplied-Ecuadorian case. In: Sixth IEEE/PES transmission and distribution: Latin America conference and exposition (T\&D-LA), 2012. p. 1-9. 